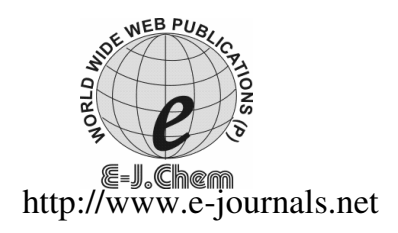

ISSN: 0973-4945; CODEN ECJHAO

E-Journal of Chemistry

2011, 8(3), 1238-1245

\title{
A Validated RP-HPLC Method for Simultaneous Estimation of Atenolol and Indapamide in Pharmaceutical Formulations
}

\author{
G.TULJA RANI*, D. GOWRI SANKAR ${ }^{\S}$, \\ P. KADGAPATHI ${ }^{\#}$ and B. SATYANARAYANA \\ *Department of Pharmaceutical Analysis \\ Sarojini Naidu Vanitha Pharmacy Maha Vidyalaya \\ Exhibition Grounds, Nampally, Hyderabad-500001, India \\ ${ }^{\S}$ Department of Pharmaceutical Analysis and Quality Assurance \\ University College of Pharmaceutical Sciences \\ Andhra University, Visakhapatnam-530003, India \\ ${ }^{\#}$ Hetero Drugs Ltd. Balanagar, Hyderabad-500055, India \\ Neosun Biotech (India) Pvt, Ltd., Hyderabad-500007 India \\ tuljapharma@yahoo.com
}

Received 19 September 2010; Accepted 22 November 2010

\begin{abstract}
A simple, fast, precise, selective and accurate RP-HPLC method was developed and validated for the simultaneous determination of atenolol and indapamide from bulk and formulations. Chromatographic separation was achieved isocratically on a Waters C18 column $(250 \times 4.6 \mathrm{~mm}, 5 \mu$ particle size $)$ using a mobile phase, methanol and water (adjusted to $\mathrm{pH} 2.7$ with $1 \%$ orthophosphoric acid) in the ratio of 80:20. The flow rate was $1 \mathrm{~mL} / \mathrm{min}$ and effluent was detected at $230 \mathrm{~nm}$. The retention time of atenolol and indapamide were $1.766 \mathrm{~min}$ and $3.407 \mathrm{~min}$. respectively. Linearity was observed in the concentration range of $12.5-150 \mu \mathrm{g} / \mathrm{mL}$ for atenolol and $0.625-7.5 \mu \mathrm{g} / \mathrm{mL}$ for indapamide. Percent recoveries obtained for both the drugs were $99.74-100.06 \%$ and $98.65-99.98 \%$, respectively. The method was validated according to the ICH guidelines with respect to specificity, linearity, accuracy, precision and robustness. The method developed can be used for the routine analysis of atenolol and indapamide from their combined dosage form.
\end{abstract}

Keywords: Atenolol, Indapamide, RP-HPLC, Validation

\section{Introduction}

Atenolol is a beta ( $\beta 1)$ selective (cardioselective) adrenoceptor blocking agent. The main uses of atenolol are in the treatment of hypertension and coronary heart disease. The chemical 
name of atenolol is 4-[2-hydroxy-3-(1-metyl ethyl amino) propyl] benzene acetamide (Figure 1a). Indapamide is a non-thiazide sulphonamide diuretic drug, generally used in the treatment of hypertension, as well as decompensated cardiac failure. Chemically indapamide is 3-(amino sulfonyl)-2methyl-4-imdol-1-yl) benzamide (Figure 1b).<smiles>CC(C)NCC(O)COc1ccc(CC(N)=O)cc1</smiles>

Figure 1a. Structure of atenolol<smiles>CC1Cc2ccccc2N1NC(=O)c1ccc(Cl)c(S(N)(=O)=O)c1</smiles>

Figure 1b. Structure of indapamide

Literature survey reveals that there are several analytical methods ${ }^{1-13}$ for the estimation of atenolol and indapamide individually or in combination with other drugs. Although the combinational use of atenolol and indapamide is continuously increasing, there is no RP-HPLC method for the determination of these drugs in combined dosage form. So the availability of HPLC method with high sensitivity will be very useful for the simultaneous determination of atenolol and indapamide in combined dosage form. Hence a new RP-HPLC method has been developed for the estimation of atenolol and indapamide in combined dosage form using UV-visible detector. The developed method is simple, precise, selective, and rapid and can be used for routine analysis.

\section{Experimental}

Chromatographic separation was performed on a Shimadzu chromatographic system, equipped with Lc-10AT VP series pump, rheodyne injector with $20 \mu \mathrm{L}$ fixed volume loop, UV- visible detector SPD-10AVP and the output signal was monitored and integrated by spinchrome software. Waters C-18 column $(250 \mathrm{~mm} \times 4.6 \mathrm{~mm}$ i.d; particle size $5 \mu \mathrm{m})$ was used for separation. Shimadzu UV-1800 double beam UV-visible spectrophotometer was used to carry out spectral analysis.

The drug samples, atenolol and indapamide were obtained as gift samples from M/S Aurobindo Pharmaceticals Ltd., Hyderabad, Andhra Pradesh, India). Tablet A (ATELOL-D, THEMIS) and Tablet B (ATEMIDE, ALKEM, Mumbai, India) are procured from local drug store. Methanol of HPLC grade and other reagents used in this study were of analytical grade (S.D. Fine chemicals Ltd., Mumbai, India.) Triple distilled water was used to carry out the analysis.

\section{HPLC Conditions}

The contents of the mobile phase were methanol and water (adjusted to $\mathrm{pH} 2.7$ with $1 \%$ orthophosphoric acid) in the ratio of 80:20 v/v. They were filtered through $0.45 \mu \mathrm{m}$ membrane filter, sonicated for $15 \mathrm{~min}$. and pumped from the respective solvent reservoirs to the column at a flow rate of $1 \mathrm{~mL} / \mathrm{min}$. The run time was set at $10 \mathrm{~min}$ and column temperature was ambient. Prior to the injection of the drug solution, the column was equilibrated for at least $0.5 \mathrm{~h}$ with the mobile phase flowing through the system. The analytes were monitored at $230 \mathrm{~nm}$.

\section{Preparation of standard stock solutions}

Standard stock solutions of atenolol and indapamide were prepared separately by dissolving $25 \mathrm{mg}$ of each drug in $25 \mathrm{~mL}$ volumetric flask with $10 \mathrm{~mL}$ of mobile phase and the solutions were sonicated for about $15 \mathrm{~min}$. Then the volume was made up to the mark with mobile phase to get $1 \mathrm{mg} / \mathrm{mL}$ standard stock solution. 


\section{Calibration curve}

From this stock solution, mixed standard solutions having ratio 20:1 (atenolol and indapamide) were prepared using mobile phase and were found to be linear in the range $12.5-150 \mu \mathrm{g} / \mathrm{mL}$ for atenolol and $0.625-7.5 \mu \mathrm{g} / \mathrm{mL}$ for indapamide. All the drug solutions $(20 \mu \mathrm{L})$ were injected separately for six times into the column, the peak area and the retention time were recorded. Calibration curves were obtained by plotting peak areas $v s$ concentrations of atenolol and indapamide. The regression equation was used to estimate the amount of atenolol and indapamide in combined dosage form.

\section{Procedure for assay}

Twenty tablets of Tablet A and Tablet B each containing $50 \mathrm{mg}$ of atenolol and $2.5 \mathrm{mg}$ of indapamide were accurately weighed and finely powdered. Tablet powder equivalent to $20 \mathrm{mg}$ of atenolol and $1 \mathrm{mg}$ of indapamide was taken into a $10 \mathrm{~mL}$ volumetric flask and dissolved in $5.0 \mathrm{~mL}$ of mobile phase. Then the solution was sonicated for complete solubility of the drugs and the volume was made up to the mark with mobile phase. From this $0.4 \mathrm{~mL}$ of the solution was taken into another $10 \mathrm{~mL}$ volumetric flask and made up the volume using the mobile phase. The solution was filtered through $0.35 \mu \mathrm{m}$ membrane filter and $20 \mu \mathrm{L}$ of sample preparation was injected into injector of liquid chromatographic system. The assay procedure was repeated for five times and the chromatogram was recorded. The results of analysis of tablet dosage form are presented ( $c f$. Table 5)

Table 1. Optimised chromatographic conditions

\begin{tabular}{cc}
\hline Parameters & Method \\
\hline & Shimadzu Lc-10AT liquid pump, SPD-10A \\
Stationary phase (column) & UV-visible detector, a waters C-18 RP-HPLC \\
& column $(250 \times 4.6 \mathrm{~mm} 5 \mu \mathrm{m}$, I.D) \\
Mobile phase & Methanol: water (adjusted to pH 2.7 with 1\% \\
ortho phosphoric acid) $80: 20 \mathrm{v} / \mathrm{v}$ \\
Flow rate, $\mathrm{mL} / \mathrm{min}$ & 1 \\
Runtime, min & 10 \\
Column temperature, ${ }^{0} \mathrm{C}$ & Ambient \\
Volume of injection loop, $\mu \mathrm{L}$ & 20 \\
Detection wavelength, $\mathrm{nm}$ & 230 \\
\hline
\end{tabular}

\section{System suitability parameters}

System suitability tests are an integral part of chromatographic method. They were used to verify that the reproducibility of the chromatographic system is adequate for the analysis. To ascertain its effectiveness, system suitability tests were carried out on freshly prepared standard stock solution of atenolol and indapamide. In addition, standard deviation of atenolol and indapamide standards was evaluated by injecting mixed standard of both atenolol and indapamide. All the parameters are presented in Table 2.

Table 2. System suitability test parameters

\begin{tabular}{ccc}
\hline Parameter & Atenolol & Indapamide \\
\hline Retention Time $^{*}$, min & 1.766 & 3.407 \\
${\text { Theoretical plates }(\mathrm{N}){ }^{*}}$ & 5380 & 1229 \\
Tailing factor $(\mathrm{F}) *^{*}$ & 0.972 & 1.450 \\
Resolution $^{*}$ & - & 8.567 \\
\hline
\end{tabular}

*Each value is the mean of 6 determinations 


\section{Validation of the method}

The method was validated, in accordance with ICH guidelines, for linearity, accuracy, precision, specificity, sensitivity, ruggedness and robustness.

\section{Linearity}

Linearity was assessed with the aid of serially diluted calibration solutions as mentioned above. The standards were injected separately. Calibration curve was constructed by plotting average peak areas against concentration and regression equation was computed. The results were presented in Table 3 which shows that an excellent correlation existed between the peak area and concentration range. Regression graph was shown at Figure 4 and 5 and the linear correlations were obtained over the range studied, with correlation coefficients $\geq 0.99$ for both the drugs. Linear regression equation being $\mathrm{Y}=51.574 \mathrm{X}-99.189$ and 68.042X-7.476 for atenolol and indapamide, respectively.

\section{Precision}

The precision of the method was demonstrated by intra day and inter day studies. The intra day and inter day studies were carried out repeatedly for standard and sample solution by injecting six times on the same day and on three consecutive days, respectively. The response factor of the drug peaks and percentage RSD were calculated. From the data obtained, the developed HPLC method was found to be precise and the results are presented in Table 3.

Table 3. Validation parameters

\begin{tabular}{ccc}
\hline Parameters & Atenolol & Indapamide \\
\hline Calibration range, $\mu \mathrm{g} / \mathrm{mL}$ & $0.625-7.50$ & $12.5-150$ \\
Regression equation & $51.574 x-99.189$ & $68.042-7.647$ \\
Y=mx+c & 51.574 & 68.042 \\
Slope $(\mathrm{m})$ & -99.189 & -7.647 \\
Intercept $(\mathrm{c})$ & 0.999 & 0.9993 \\
LOD, $\mu \mathrm{g} / \mathrm{mL}$ & 0.11 & 0.14 \\
LOQ, $\mu \mathrm{g} / \mathrm{mL}$ & 0.34 & 0.42 \\
Intra day precision, \%RSD & 0.6383 & 0.9942 \\
Inter day precision, \%RSD & 0.3776 & 0.6922 \\
\hline
\end{tabular}

*Average of six determinations

\section{Accuracy}

To study the reliability, suitability and accuracy of the method recovery studies were carried out. A known quantity of the pure drug was added to the pre-analyzed sample formulation at the level of 50\%, 100\% and 150\% and further dilutions were made and the concentration of the drugs were determined from calibration curve. Recovery studies were carried out six times and the percentage recovery was calculated and presented in Table. 4 . The lower value of \%RSD indicates the method is accurate. The mean recoveries were in the range of 99.65-100.06\%, which shows that there is no interference with excipients. The percent recoveries were calculated by using the following equation.

$$
\% \text { Recovery }=\frac{\mathrm{b}-\mathrm{a}}{\mathrm{c}} \times 100
$$

Where,

a- The amount of drug found before the addition of standard drug

b- The amount of drug found after the addition of the standard drug

c- The amount of standard drug added 
Table 4. Results of the recovery study

\begin{tabular}{ccc}
\hline & \multicolumn{2}{c}{ \%Recovery $^{*} \pm$ SD } \\
\cline { 2 - 3 } Sample & Atenolol & Indapamide \\
\hline S1 50\% & $100.06 \pm 0.10$ & $99.65 \pm 0.385$ \\
S2 100\% & $100.02 \pm 0.11$ & $99.98 \pm 0.260$ \\
S3 150\% & $99.74 \pm 0.348$ & $99.83 \pm 0.235$ \\
\hline
\end{tabular}

"Mean of six determinations

\section{Specificity}

Specificity was tested against standard compounds and against potential interferences in the presence of placebo. No interference was detected at the retention time of atenolol and indapamide in sample solution.

\section{Stability}

To demonstrate the stability of both standard and sample drug solutions during analysis, both the solutions were analyzed over a period of $24 \mathrm{~h}$ at room temperature. For both the solutions, the results showed that, the retention times and peak areas of atenolol and indapamide remained almost unchanged indicating that no significant degradation occurred within $24 \mathrm{~h}$. Sample solutions were then stored at 4 and $25{ }^{\circ} \mathrm{C}$ and after three days of storage, the results were compared with those from freshly prepared sample solution. No significant degradation occurred within this period.

\section{Robustness}

The robustness of the method was determined by making slight changes in the chromatographic conditions (Water $\mathrm{pH} \pm 0.2$, flow rate $\pm 0.2 \mathrm{~mL}$ ). It was observed that there was no marked change in the chromatograms which demonstrates that the developed RP-HPLC method is robust. When the mobile phase composition was changed by $\pm 10 \%$, proper resolution could not be achieved and the separation of the drugs was sensitive to the change in the mobile phase ratio.

\section{Limit of detection}

The limit of detection (LOD) is the smallest concentration that can be detected but not necessarily quantified as an exact value. The LOD of atenolol and indapamide was found to be $0.11 \mu \mathrm{g} / \mathrm{mL}$ and $0.14 \mu \mathrm{g} / \mathrm{mL}$ that were calculated by using the following equation.

$$
\text { LOD }=\frac{3.3 \times \text { Standard deviation of } Y \text { intercept }}{\text { Slope of calibration curve }}
$$

\section{Limit of quantitation}

The limit of quantitation (LOQ) is the lowest amount of analyte in the sample that can be determined with suitable precision and accuracy. The LOQ of atenolol and indapamide was 0.34 and $0.42 \mu \mathrm{g} / \mathrm{mL}$, respectively which was calculated by using the following equation.

$$
\mathrm{LOQ}=\frac{10 \times \text { Standard deviation of } \mathrm{y} \text { intercept }}{\text { Slope of calibration curve }}
$$

\section{Results and Discussion}

The objective of this study was to develop simple, sensitive and rapid RP-HPLC method for the simultaneous estimation of atenolol and indapamide in its combined dosage forms. Various solvent systems were tried and finally a mixture of methanol and water (adjusted to 
pH 2.7 with $1 \%$ orthophosphoric acid) in the ratio of $80: 20(\mathrm{v} / \mathrm{v})$, proved to be effective to separate atenolol and indapamide with resolution of 8.567. Then the flow rate tested includes $0.4,0.8,1.0,1.2$ and $1.5 \mathrm{~mL}$ and out of which the flow rate $1.0 \mathrm{~mL}$ was selected for the assay because of better resolution of the peaks. The overlaid UV spectrum of atenolol and indapamide was recorded and shown in Figure 2.

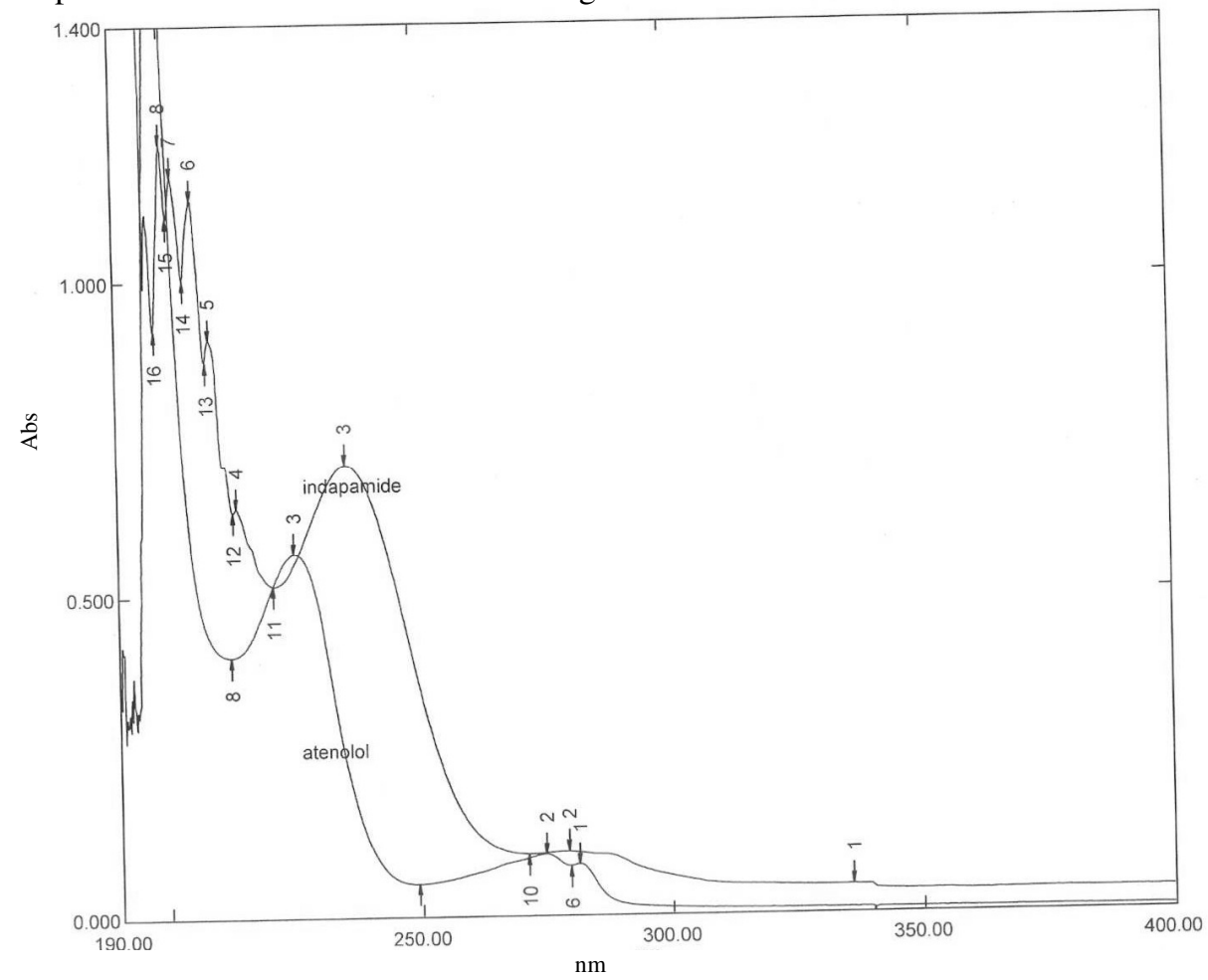

Figure 2. Overlaid spectrum of atenolol and indapamide

A typical chromatogram of atenolol and indapamide is shown in Figure.3. The retention time of atenolol and indapamide was found to be 1.766 and 3.407 minutes respectively. The calibration curve of atenolol and indapamide was constructed by plotting the peak areas of the drugs to the concentrations. It was found to be linear at the concentration range of $12.5-150 \mu \mathrm{g} / \mathrm{mL}$ for atenolol and $0.625-7.5 \mu \mathrm{g} / \mathrm{mL}$ for indapamide with a corresponding correlation coefficient of 0.999 for atenolol and 0.9993 for indapamide (Figure 4, 5). When a known amount of pure drug solutions were added to the powder sample of tablet dosage form at three different levels and subjected to estimation of the drugs by the proposed method, there was a high recovery of atenolol and indapamide, indicating that the proposed method is highly accurate (Table 4). The intra-day and inter -day variations of the method was studied on the same day and on three different days and observed low \%RSD (Table 3). This shows that the present HPLC method is highly precise. The tablets were found to contain 99.92 to $100.07 \%$ of atenolol and 99.92 to $99.98 \%$ of indapamide (Table 5). The limit of detection and limit of quantification for atenolol was found to be 0.11 and $0.34 \mu \mathrm{g} / \mathrm{mL}$ respectively and for indapamide, 0.14 and $0.42 \mu \mathrm{g} / \mathrm{mL}$ respectively, which suggests that nanogram quantity of drugs, can be estimated accurately. The proposed method was found to be specific as there is no interference from commonly used excipients. 


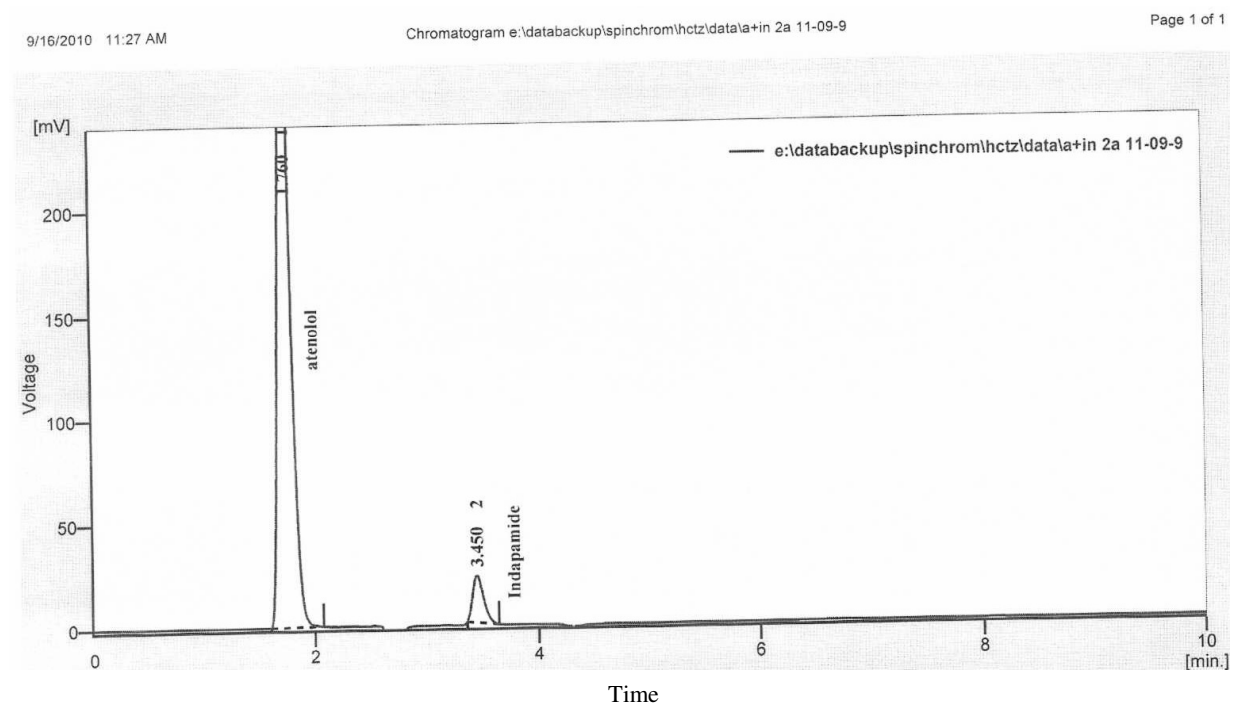

Figure 3. A typical chromatogram of atenolol and indapamide

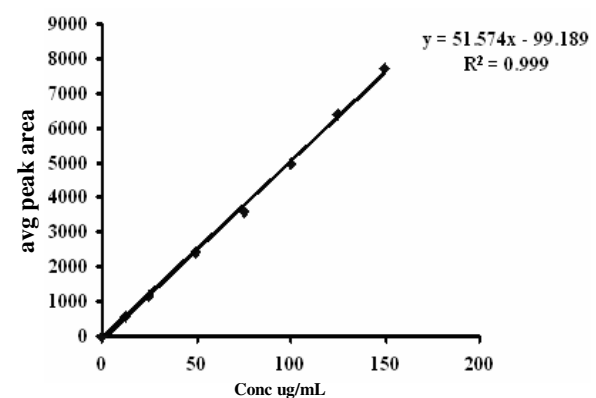

Figure 4. Calibration curve of atenolol

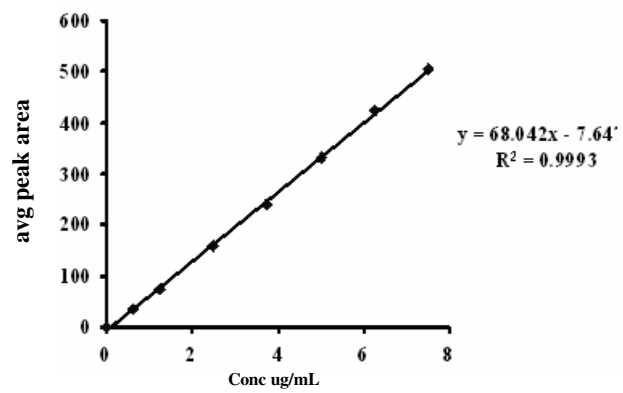

Figure 5. Calibration curve of indapamide

Table 5. Results of Analysis of formulation by the proposed

\begin{tabular}{ccccccc}
\hline & \multicolumn{2}{c}{ Labeled amount, $\mathrm{mg}$} & \multicolumn{2}{c}{ Amount obtained,mg ${ }^{\mathrm{a}} \pm$ S.D } & \multicolumn{2}{c}{ \% Label claim } \\
\hline Formulation & Atenolol & Indapamide & Atenolol & Indapamide & Atenolol & Indapamide \\
A & 50 & 2.5 & $49.96 \pm 0.256$ & $2.495 \pm 0.349$ & $99.92 \pm 0.096$ & $99.8 \pm 0.384$ \\
B & 50 & 2.5 & $50.03 \pm 0.182$ & $2.498 \pm 0.281$ & $100.07 \pm 0.451$ & $99.92 \pm 0.461$ \\
\hline
\end{tabular}

${ }^{a}$ Mean value \pm standard deviation of 5 determinations

\section{Conclusion}

The proposed RP-HPLC method for simultaneous determination of atenolol and indapamide in combined tablets dosage forms is simple, precise, specific and highly accurate and less time consumption for analysis. Mobile phase used for this method is less expensive and can be used for the routine analysis of these drugs in combined dosage forms.

\section{Acknowledgments}

The authors thank to the principal, Dr.S.K.Gulati, HOD, Dr.K.Ramasubha reddy and management of Sarojini Naidu Vanitha Pharmacy Maha Vidyalaya for providing necessary facilities. The authors also thank to M/S Aurobindo Pharmaceticals Ltd., Hyderabad, Andhra Pradesh, India for providing gift samples of drugs. 


\section{References}

1. Barman R K, Islam M A U and Ahmed M, Wahed M I I, Islam R, Khan A, Hossain M B and Rahman B M, Pak J Pharm Sci., 2007, 20(4), 274-279.

2. Zvi Teitelbaum, Naomi Ben-dom and Sarah Terry, J Liq Chromatogr., 1991, 14(20), 3735-3744.

3 Naveen Kumar, Nishant Verma, Omveer Songh, Naveen Joshi and Kanwar Gaurav Singh, E- J Chem., 2010, 7(3), 962-966.

4. Bhatia N M, Mohite A S and Bhatia M S, The Indian Pharmacist, 2007, 6, 59-62.

5. Sankar S Ravi, Nanjan M J, Vasudevan M, Shaat N, Suresh B and Sankar S R, Indian J Pharm Sci., 1997, 59(4), 171-173.

6. Vishnu P Choudhari, Vishnu M Suryawanshi, Rashmi H Mahabal, Sayali G Deshchougule, Kishor P Bhalerao and Bhanudas S Kuchekar, Int J Pharm Sci., 2010, 3(1), 73-76.

7. Kasture A V and Madhuri Ramteke, Indian J Pham Sci., 2006, 68(3), 394-396.

8. Kasture A V and Madhuri Ramteke, Indian J Pham Sci., 2005, 67(6), 752-754.

9. Ilango K, Kumar P B and Lakshmi K S, Indian Drugs, 2000, 37, 497-499.

10. Singhvi and Anju Goyal, Indian J Pharm Sci., 2007, 69(1), 164-165.

11. Ribeiro D S M, Prior J A V, Santos J L M, Lopes J A and Lima J L F C, Talanta., 2009, 79(4), 1161-1168.

12. Sivakuma T, Venkateshan P, Manavalan R and Valliappan K, Indian J Pharm Sci., 2007, 69(1), 154-157

13. Jain D S, Subbaih G, Sanyal M, Pande U C and Shivastav P, J Chromatogr B Anal Technol Biomed Life Sci., 2006, 834(1-2), 149-154. 


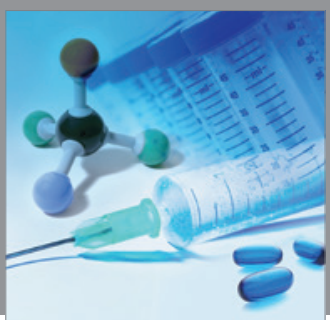

International Journal of

Medicinal Chemistry

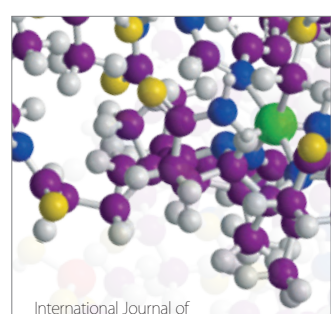

Carbohydrate Chemistry

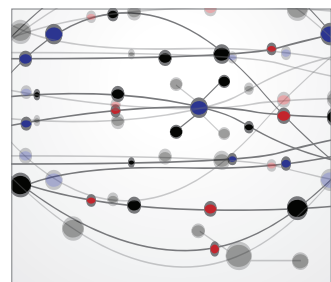

The Scientific World Journal
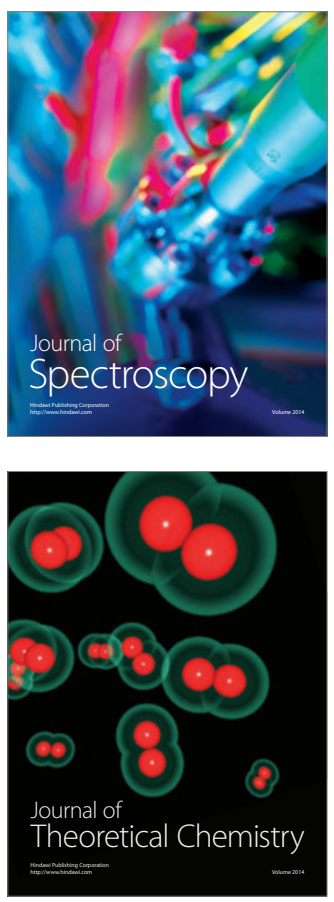
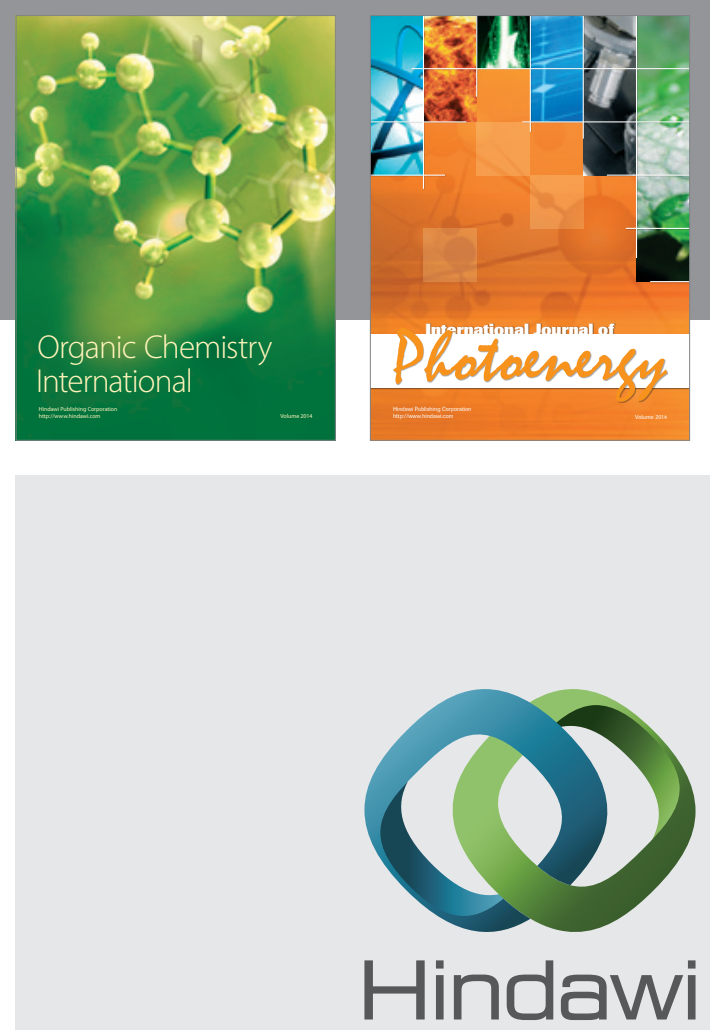

Submit your manuscripts at

http://www.hindawi.com
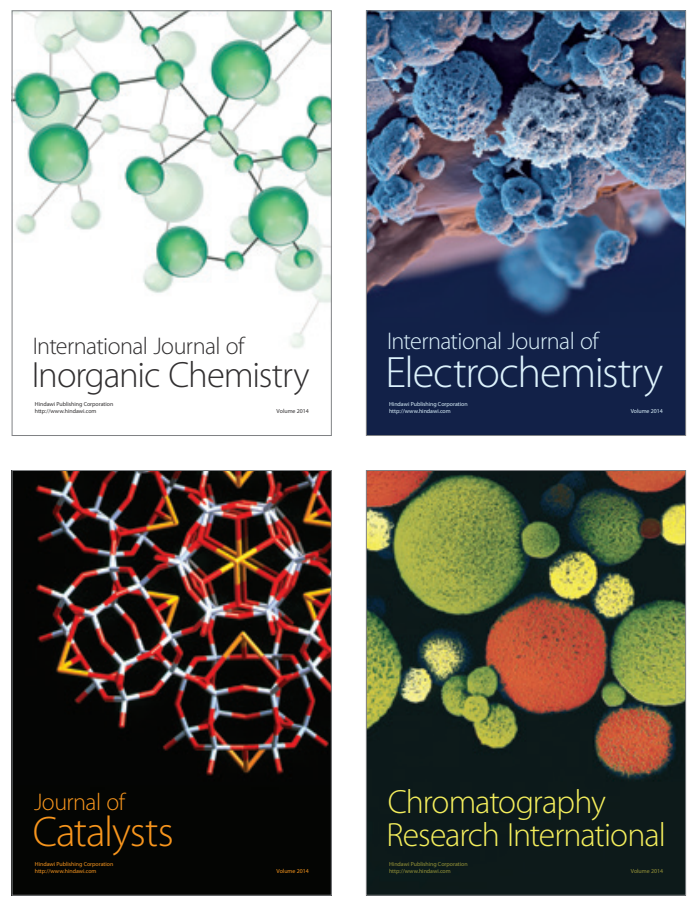
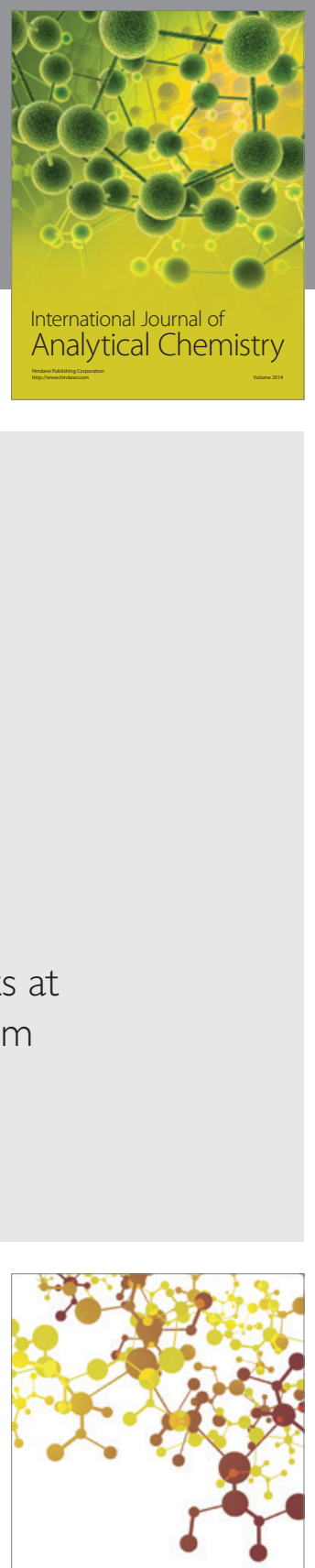

Journal of

Applied Chemistry
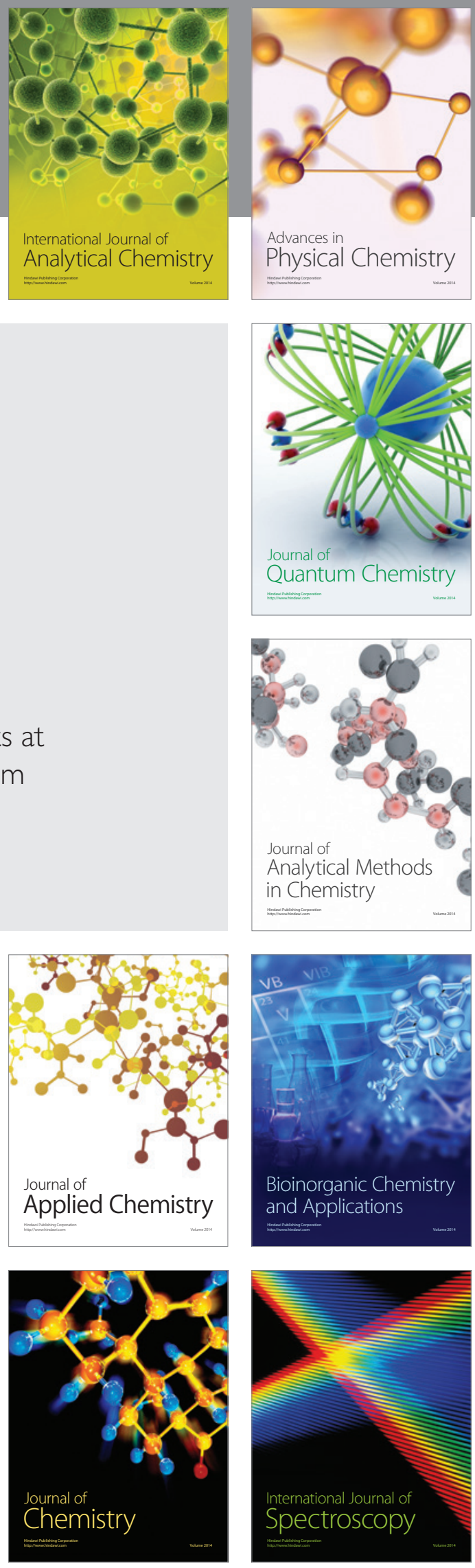